\title{
Editorial - Volume 4, Number 1
}

Citation: Cannon, R. L. (2017). Editorial - Volume 4, Number 1. NeuroRegulation, 4(1), 2. http://dx.doi.org/10.15540/nr.4.1.2

Copyright: (c) 2017. Cannon. This is an Open Access article distributed under the terms of the Creative Commons Attribution License (CC-BY).
*Address correspondence to: Rex L. Cannon, PhD, BCN, Neurogifted, 10151 Enterprise Center Blvd, Ste 207, Boynton Beach, FL 33437, USA. Email: rcannonphd@gmail.com
Welcome to Volume 4, Issue 1 of NeuroRegulation! As the increased exposure and interest in neurofeedback and applied neuroscience continues to grow, we are excited to see increased submissions to NeuroRegulation.

With this fourth volume of NeuroRegulation we are excited to introduce a special invited paper series focused on providing clear, unambiguous definitions for the concepts and methods used in neurofeedback and applied neuroscience. It is often very difficult to find clear operant definitions for many of the concepts used in the processes of neurofeedback, applied neuroscience, or quantitative electroencephalographic (qEEG) research. It is our goal to solicit experts and leaders to provide these reference articles so that young researchers and veteran clinicians can find clear information about neurofeedback, quantitative EEG, and applied neuroscience without proprietary conflicts being present. In this issue, Scott Decker, Paul Fillmore, and Alycia Roberts provide a reference article for coherence. Estate Sokhadze, Manuel Casanova, Emily Casanova, Eva Lamina, Desmond Kelly, and Irma Khachidze contribute a reference article for event-related potentials (ERP) in cognitive neuroscience. It is with great honor we received these contributions and we express sincere gratitude to these authors for kicking off this invited paper series. It is extremely important in science and clinical work to provide clear, definitions for the core components of a methodology. We will continue this series over the course of 2017 and hope to receive articles for all core concepts in neurofeedback and EEG.
Additionally in this issue, authors present numerous topics of interest to researchers, clinicians, and the public. Ed Pigott presents a thoughtful confrontation of difficulties in neuropharmacology and emphasizes the important role neuromodulation and learning techniques play in future evidence-based models for treating psychological issues. Elyse White, Kayleah Groeneveld, Rachel Tittle, Nicholas Bolhuis, Rachel Martin, Timothy Royer, and Majid Fotuhi present data examining the effects of combined neurofeedback and heart rate variability on symptoms of anxiety and depression. Erin Maclnerney, Ronald Swatzyna, Alexandra Roark, Bianca Gonzalez, and Gerald Kozlowsi present a case study of the importance of breakfast and breakfast choices on the EEG.

NeuroRegulation thanks these authors for their valuable contributions to the scientific literature for neurofeedback and quantitative EEG. We strive for high quality and interesting empirical topics. We encourage the members of ISNR and other biofeedback and neuroscience disciplines to consider publishing with us. It is important to stress that publication of case reports is always useful in furthering the advancement of an intervention for both clinical and normative functioning. Thus, we encourage all individuals practicing neurofeedback to submit case studies! We thank you for reading NeuroRegulation! Additionally, NeuroRegulation is on Facebook, drop by and like our page.

Rex L. Cannon, PhD, BCN

Editor-in-Chief

Email: rcannonphd@gmail.com 